\title{
Mineração
}

\section{Reciclagem de aminas na flotação de minério de ferro}

\section{(Recycling of amines present in the residues from the reverse flotation of iron ore)}

\author{
Danielle M. Araujo \\ Doutoranda, Departamento de Química, ICEx, UFMG \\ E-mail:danimara@qui.ufmg.br
}

\author{
Maria Irene Yoshida \\ Professora, Dra., Departamento de Química, ICEx, UFMG \\ E-mail:mirene@ufmg.br \\ Cornélio F. Carvalho \\ Professor, Dr., Departamento de Química, ICEB, UFOP \\ E-mail:cornelio@iceb.ufop.br \\ Frank Stapelfeldt \\ Dr. Ing., Consultor, Belo Horizonte \\ E-mail:stapelfeldt@yahoo.com
}

\section{Resumo}

O presente trabalho tem por objetivo investigar a possibilidade de reutilização de aminas residuais provenientes do processo de flotação de minério de ferro. Os testes de flotação em bancada foram realizados em $\mathrm{pH}$ 10,5, tendo o amido como depressor dos óxidos de ferro e as aminas Flotigam EDA 3B e F2835 como coletores para a sílica. Cada rejeito desses ensaios foi submetido à separação sólido/líquido através de filtração a vácuo. $\mathrm{O}$ líquido contendo amina residual foi reutilizado em um segundo ensaio de flotação, onde foi investigada a dosagem de reagente novo. Utilizando-se a água contendo amina residual, juntamente com quantidades novas dos coletores, observou-se que há a possibilidade de diminuir o consumo desse reagente em até 50\%. Foi realizado também teste de dessorção das aminas contidas em rejeitos sólidos, adicionando-se água ao resíduo em diferentes valores de $\mathrm{pH}$ e massa do resíduo. Os resultados revelaram que mais de $95 \%$ da amina adicionada pode ser recuperada.

Palavras-chave: Flotação reversa, reciclagem, aminas graxas.

\begin{abstract}
The present work has the objective of investigating the possibility of the reuse of residual amines resulting from the process of reverse flotation of iron ore. Benchscale flotation tests were performed at $\mathrm{pH} 10.5$ with starch as the depressant of iron oxides and the amines Flotigam EDA 3B and F 2835 as silica collectors. Each waste effluent from these trials was submitted to solid/ liquid separation via vacuum filtration. The liquid containing residual amine was reutilized in a second flotation trial where the concentration of the new reagent was determined. Utilizing the water containing the residual amine together with new quantities of collectors, it was observed that it was possible to reduce the consumption of this reagent by as much as $50 \%$. A desorption test of the amines contained in the solid waste was performed by putting different masses of the residual in contact with water of different $\mathrm{pH}$ values. The results revealed that more than $95 \%$ of the amine added could be recovered.
\end{abstract}

Keywords: Reverse flotation, recycling, fatty amines. 


\section{Introdução}

As reservas mundiais de minério de ferro são da ordem de 330 bilhões de toneladas, sendo que o Brasil possui 7,1\% dessas reservas e está em quinto lugar entre os países detentores de maiores quantidades de minério. Porém o alto teor de ferro em seus minérios (60 a 67\% nas hematitas e 50 a $60 \%$ nos itabiritos) leva o Brasil a ocupar um lugar de destaque no cenário mundial, em termos de ferro contido no minério. A produção mundial de minério de ferro em 2006 foi de 1,69 bilhão de toneladas. Já a produção brasileira foi de aproximadamente 317 milhões de toneladas de minério de ferro, representando cerca de $18,8 \%$ da produção mundial (Alves, 2006; DNPM, 2006 e 2007).

Os minérios ricos em ferro normalmente são submetidos aos processos de fragmentação e classificação. Devido à crescente demanda, os depósitos de minério de ferro de altos teores vem diminuindo, sendo necessário concentrar minérios com teores cada vez mais baixos. A flotação catiônica reversa é a forma de beneficiamento mais utilizada para a concentração de minérios de ferro de baixo teor, como os itabiritos brasileiros, e as aminas graxas são os coletores catiônicos mais importantes e os únicos usados industrialmente (Numela \& Iwasaki, 1986; Leja, 1983; Houot, 1983).

A flotação consiste, basicamente, na separação seletiva entre as partículas de quartzo e os óxidos de ferro. A amina graxa é adicionada ao sistema, sendo adsorvida na superfície do quartzo e ambos são removidos na forma de espuma do sistema. Entretanto, na faixa de $\mathrm{pH}$ próximo a 10, em que ocorre a flotação, tanto a superfície do quartzo, quanto da hematita, estão carregadas negativamente e poderiam adsorver a amina, embora a atração seja maior para o quartzo. Para evitar que o óxido de ferro seja flotado, é utilizado o amido como depressor (Numela \& Iwasaki, 1986; Leja, 1983; Houot, 1983).

Após a flotação, a maior parte das aminas utilizadas ficam retidas no material flotado (predominantemente de quart- zo), os quais são depositados nas barragens de rejeito. A possibilidade de reutilização das aminas acarretaria em considerável redução de custos operacionais, além da diminuição da quantidade de reagentes liberados para o meio ambiente. Estima-se que aproximadamente 5500 toneladas de derivados de amina sejam usados anualmente no Brasil em processos de flotação (Neder, 2005). A expectativa para os próximos anos é que o consumo de amina deverá aumentar devido à crescente demanda mundial por minério de ferro. As aminas são reagentes relativamente caros, porém importantes no processo de concentração, e chegam a representar cerca de $48 \%$ dos custos totais com reagentes no processo de flotação (Batisteli, 2007).

Poucos estudos sobre reciclagem de aminas no processo de flotação já foram realizados. Mas, já em 1977, Bahr estudou a concentração de aminas em efluentes provenientes da flotação. Os estudos encontrados normalmente envolvem a reutilização da solução contendo a amina, para uma nova flotação de minério de ferro (Reis, O. B., 2004; Stapelfeldt et al., 2002; Oliveira et al.,1996). Teodoro et al. (2004) mostraram a possibilidade de remoção dessas aminas através da adsorção em zeólitas seguida da dessorção dos produtos adsorvidos e seu reuso.

As aminas descartadas para as barragens de rejeitos são encontradas na água do efluente e adsorvidas nas partículas sólidas (predominantemente quartzo). Oliveira et al. (1996) estudaram a possibilidade de dessorção da amina adsorvida na sílica e os resultados revelaram que mais de $60 \%$ da amina adicionada pode ser recuperada. Desse total, mais de $42 \%$ foi dessorvida do quartzo e cerca de $19 \%$ se constituiu em amina residual. A interação entre a amina na forma $\mathrm{NH}_{3}^{+}$e a superfície negativa do quartzo ocorre por atração eletrostática (Fuerstenau, 1991). As espécies $\mathrm{H}^{+} \mathrm{e} \mathrm{OH}{ }^{-}$ são íons determinantes do potencial para silicatos. Desta forma, a carga elétrica, na superfície do quartzo, e, conseqüentemente, a densidade de adsorção de amina dependem do pH do sistema. Em meio ácido, a espécie $\mathrm{H}^{+}$é responsável pela redução de sítios negativos na superfície do quartzo, o que resulta na dessorção da amina (Bleier et al., 1976).

\section{Material e métodos 2.1 Caracterização das aminas e do minério de ferro}

Os coletores utilizados foram a etermonamina Flotigam EDA 3B e eterdiamina Flotigam 2835, ambas produzidas pela Clariant. As eteraminas foram caracterizadas por cromatografia líquida acoplada a espectrômetro de massas (LS-MS), Trap Agilent-1100.

As amostras de minério utilizadas para os testes de flotação em bancada foram coletadas do underflow do hidrociclone que alimenta a flotação convencional de uma grande mineradora do Estado de Minas Gerais. A análise granulométrica foi realizada através de peneiramento nas faixas de 0,210 a $0,037 \mathrm{~mm}$. A determinação de ferro foi realizada por titulação segundo a ABNT (2003). Os outros elementos (Mn, Ti, Al, Ca) foram quantificados através da espectrometria de emissão óptica plasma acoplado indutivamente (ICP-OES), marca Spectro / modelo Ciros CCD.

\subsection{Quantificação das aminas}

Para a quantificação das aminas presentes nas amostras de rejeito, foi utilizado o método colorimétrico do verde de bromocresol (Araujo et al., 2007). As leituras de absorvância foram realizadas em um espectrofotômetro Merck SQ118, com comprimento de onda de $405 \mathrm{~nm}$ e cubeta de $10 \mathrm{~mm}$.

\subsection{Testes de flotação}

Os experimentos foram realizados em uma célula de flotação de bancada da marca Denver com uma cuba de 2 litros. As condições dos testes foram: 1200rpm, $45 \%$ de sólidos, condicionamento do amido (300g/t) por 5 minutos e condicio- 
Danielle M. Araujo et al.

namento do coletor por 1 minuto e remoção da espuma. Os testes foram realizados em $\mathrm{pH}=10,5$ e dosagem do coletor de 30g/t para a EDA 3B e 40g/t para a mistura EDA 3B/F 2835 (na mistura foi utilizado $25 \%$ da EDA 3B e $75 \%$ da F 2835, em massa).

A definição da melhor dosagem dos coletores a serem utilizados foi determinada após a realização de vários testes de flotação variando a concentração dos coletores.

\subsection{Reciclagem}

Após os testes de flotação, os rejeitos obtidos, contendo predominantemente sílica e amina, foram filtrados e as frações líquidas, que ainda continham amina, foram reutilizadas em uma segunda flotação. O filtrado foi usado juntamente com adição de amina nova nas seguintes dosagens: 0\%, 20\%, 40\%, 50\% e $60 \%$, em relação à concentração inicial de amina da primeira flotação. Essa segunda flotação foi feita sob as mesmas condições da primeira. A reciclagem pode ser mais bem visualizada na Figura 1.

\subsection{Dessorção de amina de amostras sólidas}

As frações sólidas obtidas da filtração do rejeito foram submetidas a testes de dessorção de amina. Os testes de dessorção foram realizados colocandose o rejeito sólido em contato com água deionizada, sob agitação por 30 minutos. A suspensão foi filtrada e o filtrado foi analisado para a determinação da quantidade de amina dessorvida. As massas utilizadas foram 10, 25, 50, 75 e $100 \mathrm{~g}$ para um volume de água de $100 \mathrm{ml} \mathrm{e}$ variação do $\mathrm{pH}$.

\section{Resultados e discussão} 3.1 Caracterização das
aminas e do minério de ferro

A caracterização estrutural das ami- nas utilizadas nesse trabalho foi feita através da espectrometria de massas com ionização por eletrospray. Os espectros obtidos (Figuras 2 e 3) mostram a razão massa/carga (m/z) dos compostos analisados, a qual representa a massa molar de cada composto presente.

No espectro de massas da EDA 3B (Figura 2), a razão m/z em 216 mostra que o composto principal presente na amostra analisada possui massa molar de 216. Segundo dados da Empresa Clariant (1999), a EDA 3B possui a fórmula R-O$\left(\mathrm{CH}_{2}\right)_{3}-\mathrm{NH}_{2}$ e, ainda, segundo as informações, o grupo R seria composto de 10 a 12 átomos de carbono. De acordo com o espectro da Figura 2, o grupo R da EDA $3 \mathrm{~B}$ possui predominantemente 10 átomos de carbono, o que resulta na seguinte fórmula: $\mathrm{H}_{3} \mathrm{C}\left(\mathrm{CH}_{2}\right)_{9}-\mathrm{O}-\left(\mathrm{CH}_{2}\right)_{3}-\mathrm{NH}_{3}^{+}$.

As outras razões $\mathrm{m} / \mathrm{z}$ presentes no espectro da Figura 2 são devidas a impurezas e a produtos secundários presentes nas amostras. As aminas utilizadas nesse trabalho são amostras comerciais e, portanto, contêm impurezas, o que justifica a presença de outros picos nos espectros.

No espectro da F 2835, a razão m/z em 315 é a predominante (Figura 3). Na informação obtida do boletim da Empre- sa Clariant, a F 2835 possui a seguinte estrutura: R-O- $\left(\mathrm{CH}_{2}\right)_{3}-\mathrm{NH}-\left(\mathrm{CH}_{2}\right)_{3}-\mathrm{NH}_{2}$, de acordo com o espectro da Figura 3, e o grupo R da eterdiamina F 2835 é composto predominantemente de 13 átomos de carbono. Mas há também cerca de $20 \%$ de $\mathrm{m} / \mathrm{z}$ em 301 , que corresponde ao grupo R com 12 átomos de carbono.

Os resultados da análise granulométrica para o minério de ferro estão apresentados na Tabela 1. Aproximadamente $100 \%$ do material utilizado nos testes apresenta granulometria menor que 210 $\mu m$. A amostra continha também aproximadamente $22 \%$ de partículas ultrafinas inferiores a $37 \mu \mathrm{m}$.

A Tabela 2 apresenta os teores, em massa, dos principais componentes presentes na amostra do minério de ferro. $\mathrm{O}$ teor de ferro foi de 52,54\%, que é um valor bem abaixo do teor mínimo de 67,8\% necessário para fabricar pelotas de alto-forno e do teor mínimo de ferro de $67,9 \%$ necessário para redução direta.

\subsection{Reciclagem}

Com relação aos testes de reciclagem, a Tabela 3 mostra a média dos teores e a recuperação de ferro no concen-

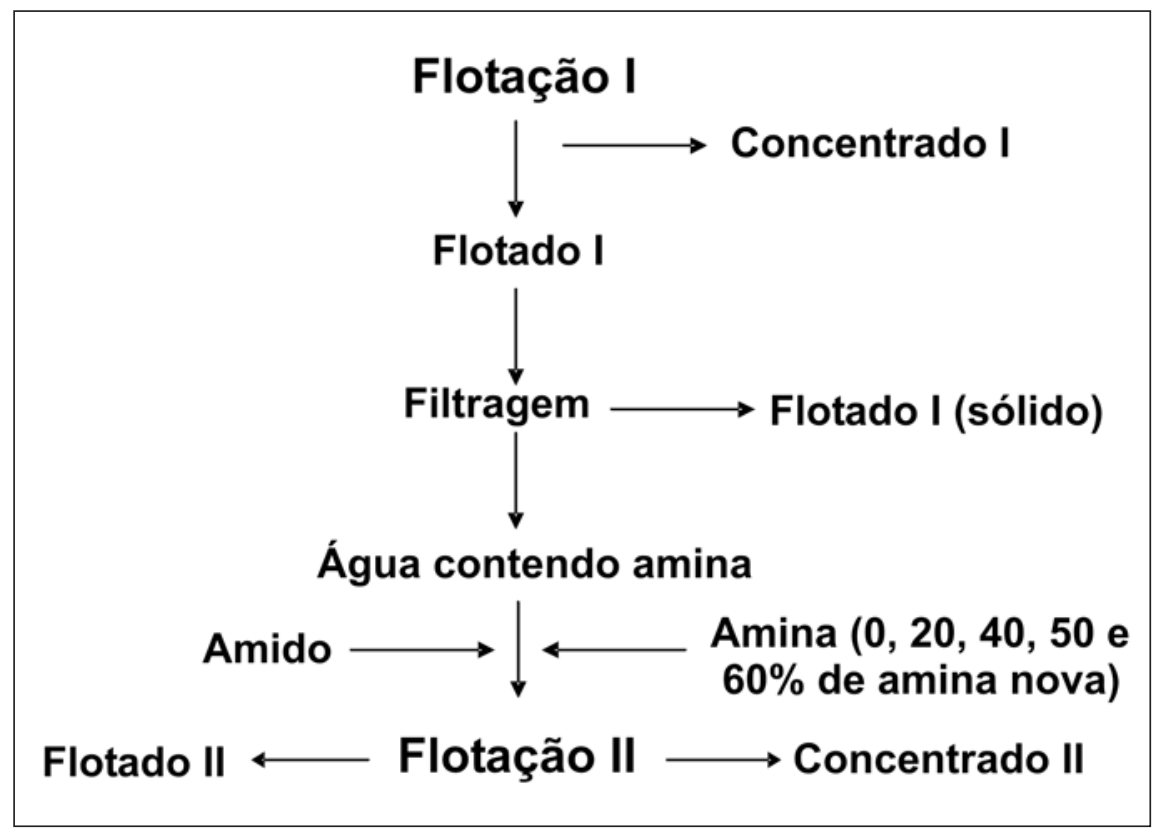

Figura 1 - Fluxograma dos testes de reciclagem. 
Reciclagem de aminas na flotação de minério de ferro

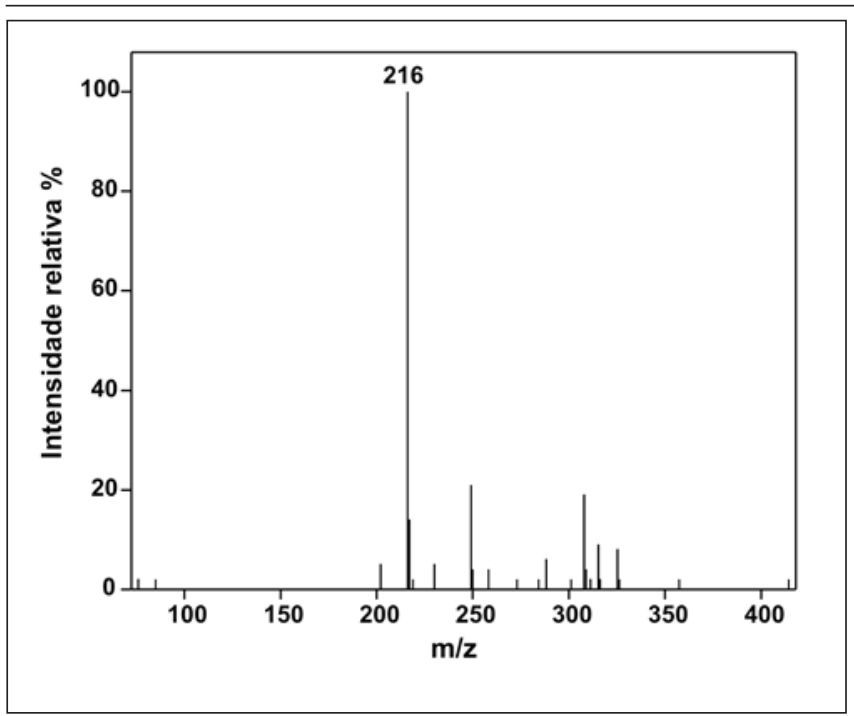

Figura 2 - Espectro de massas com ionização por eletrospray da EDA 3B em modo positivo.

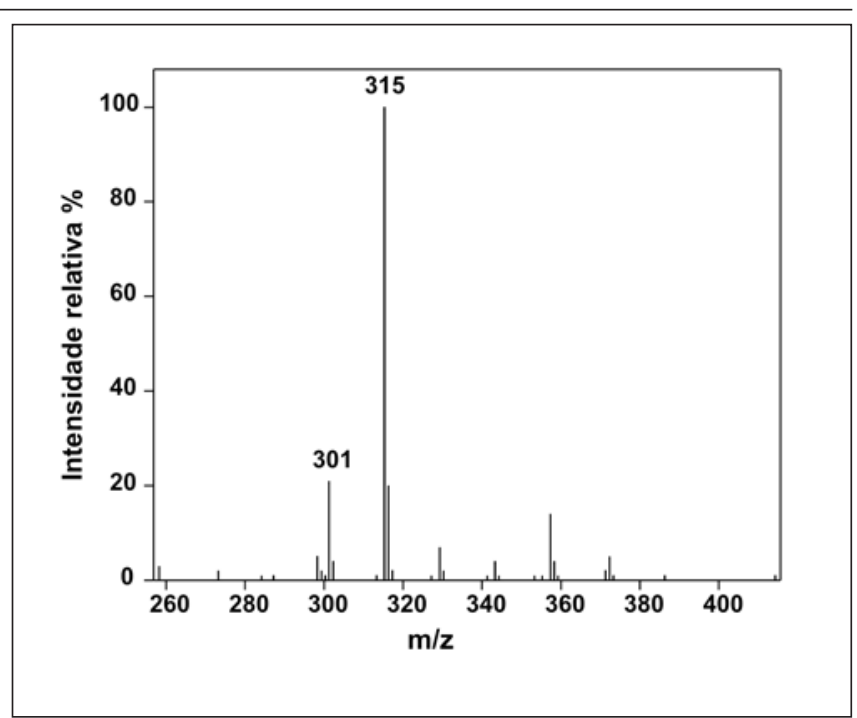

Figura 3 - Espectro de massas com ionização por eletrospray da F 2835 em modo positivo. trado da primeira etapa de flotação, onde foi adicionado $100 \%$ de amina nova. Para a EDA 3B, a dosagem foi de 30g/t e, para a mistura EDA 3B/F2835, foi de 40g/t.

As Figuras 4 e 5 mostram os teores e a recuperação de ferro no concentrado para a segunda etapa da flotação, onde foi utilizada a água do rejeito, da primeira flotação, com diferentes porcentagens de amina nova em relação à primeira flotação. Como pode ser observado, o teor de ferro aumentou de $50 \%$ para cerca de $68 \%$, com a concentração crescente do coletor, para a curva EDA 3B (Figura 4). A curva para a mistura EDA 3B e F2835 mostrou que houve aumento no teor de ferro de 54 para $66 \%$, com a concentração crescente do coletor (Figura 4). O oposto ocorre com a recuperação de ferro, que diminui com o aumento crescente de ambos os coletores (Figura 5).

Pode-se observar, ainda, que a água do flotado, juntamente com $50 \%$ e $60 \%$ de amina nova, para a EDA 3B, apresentou resultados melhores (68 e $67 \%$, respectivamente) que os testes da primeira flotação, utilizando $30 \mathrm{~g} / \mathrm{t}$, ou seja, $100 \%$ de amina nova. Os resultados da recuperação de ferro para a EDA 3B mostram que utilizando 50 e $60 \%$ de amina nova, juntamente com a água do flotado, a recuperação foi de aproximadamente 83 e $80 \%$, respectivamente, enquanto que a recuperação para a flotação utilizando
Tabela 1 - Distribuição do tamanho de partículas.

\begin{tabular}{c|c}
\hline Tamanho de Partículas $(\mu \mathrm{m})$ & Quantidade (\%) \\
\hline+210 & 3.64 \\
\hline$-210-+148$ & 8.55 \\
\hline$-148-+74$ & 28.63 \\
\hline$-74-+37$ & 37.68 \\
\hline-37 & 21.49 \\
\hline Total & 100.00 \\
\hline
\end{tabular}

Tabela 2 - Análise Química do minério de ferro.

\begin{tabular}{c|c|c|c|c|c|c|c|c}
\hline Componentes & $\mathbf{F e}$ & $\mathrm{SiO}_{2}$ & $\mathbf{A l}$ & $\mathbf{P}$ & $\mathbf{M n}$ & $\mathbf{T i}$ & $\mathbf{C a}$ & $\mathbf{M g}$ \\
\hline Teor (\%) & 52,54 & 32,5 & 0,210 & 0,026 & 0,017 & 0,010 & 0,012 & 0,012 \\
\hline
\end{tabular}

Tabela 3 - Teores e recuperação de ferro na primeira flotação

\begin{tabular}{c|c|c}
\hline Coletor utilizado & $\begin{array}{c}\text { Teor de ferro } \\
\text { (\%) }\end{array}$ & $\begin{array}{c}\text { Recuperação de ferro } \\
\mathbf{( \% )}\end{array}$ \\
\hline EDA 3B & 66,02 & 84,57 \\
\hline EDA 3B + F 2835 & 66,12 & 78,15 \\
\hline
\end{tabular}


Danielle M. Araujo et al.

$100 \%$ de amina nova foi de $84,57 \%$, em média.

Para a mistura EDA 3B e F2835, utilizando 60\% de amina nova, juntamente com a água do flotado contendo amina, foram obtidos resultados próximos aos obtidos para os testes utilizando $40 \mathrm{~g} / \mathrm{t}$ de amina nova. A recuperação de ferro, nesse caso, foi de $66 \%$, o que é similar ao resultado utilizando $40 \mathrm{~g} / \mathrm{t}$ de amina nova, e a recuperação de ferro no concentrado foi de $81 \%$, que foi melhor comparando com os $78 \%$ da primeira flotação. Para os testes utilizando $50 \%$ de coletor novo, o teor de ferro e a recuperação foram próximos dos valores obtidos para a primeira flotação, com 100\% de amina nova.

\subsection{Extração de amina de amostras sólidas}

Para os testes de extração de amina com variação de massa da amostra e volume constante da água de lavagem, foi utilizada amostra proveniente de uma empresa de mineração, a qual apresentou concentração de amina de $470 \mathrm{mg} / \mathrm{kg}$. Os resultados dos testes de extração estão demonstrados na Figura 6. Observa-se, na Figura 6, que, em $\mathrm{pH}=5$, a extração foi mais eficiente do que em $\mathrm{pH}=10$ e, dentro dessa faixa de $\mathrm{pH}$, a única relação com aproximadamente $100 \%$ de recuperação de amina foi de $10 \mathrm{~g}$ de amostra para $100 \mathrm{~mL}$ de água, enquanto que a recuperação de amina para 10 g de amostra, em $\mathrm{pH}=10$, foi de $63 \%$, em média.

O melhor rendimento de extração em $\mathrm{pH}=5$ pode ser devido ao fato de que, nessa faixa de $\mathrm{pH}$, os compostos de amina tornam-se mais solúveis em solução aquosa, facilitando, assim, sua extração. Segundo Oliveira et al. (1996), a diluição resulta na quebra do equilíbrio eletroquímico do sistema e, como conseqüência, na dessorção da amina, cujo processo é refletido na brusca variação do potencial zeta do quartzo.

\section{Conclusões}

Com os testes de flotação, verificou-se que as amostras de rejeito con-

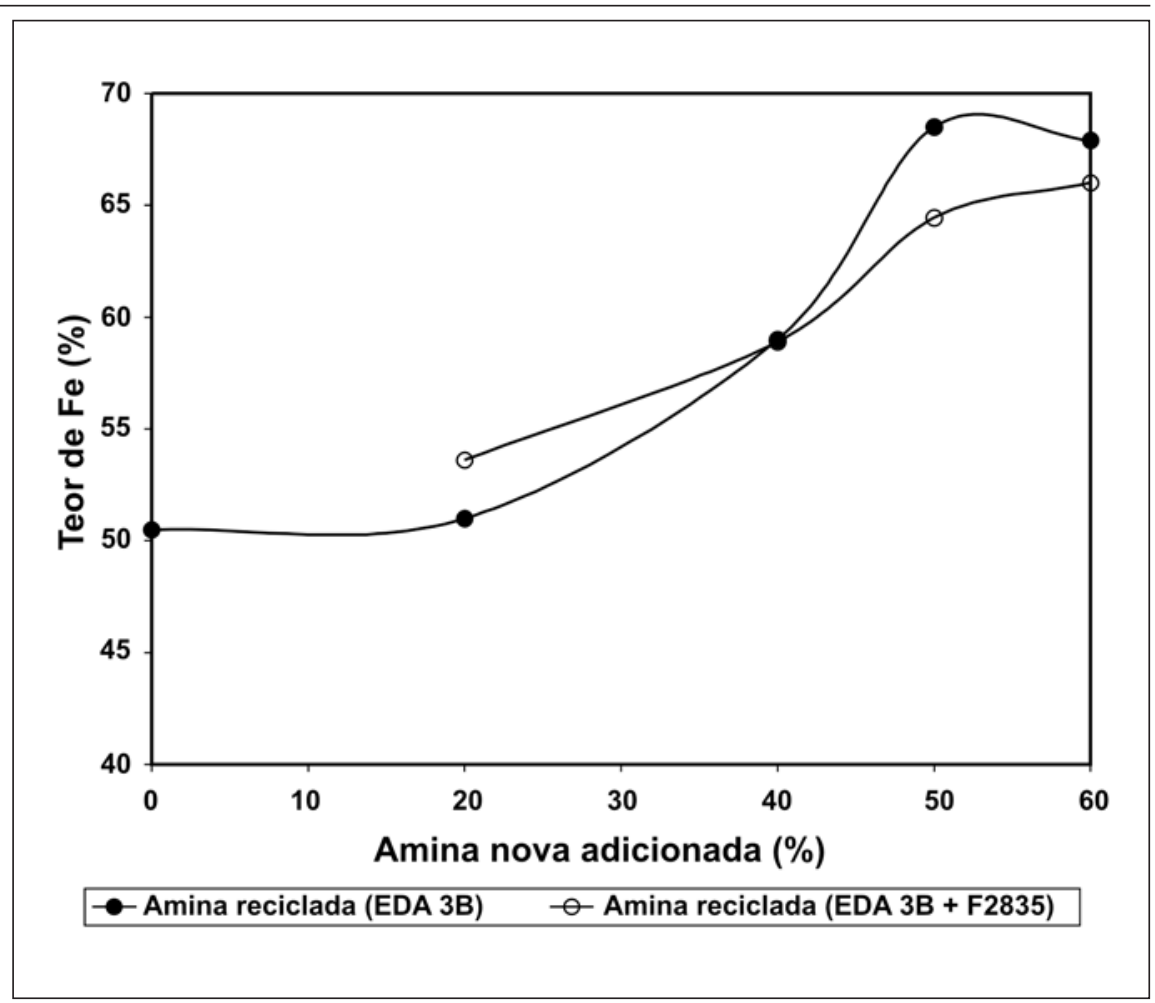

Figura 4 - Teor de ferro no concentrado em função da quantidade de amina adicionada na segunda flotação, para EDA 3B e para a mistura EDA 3B e F2835.

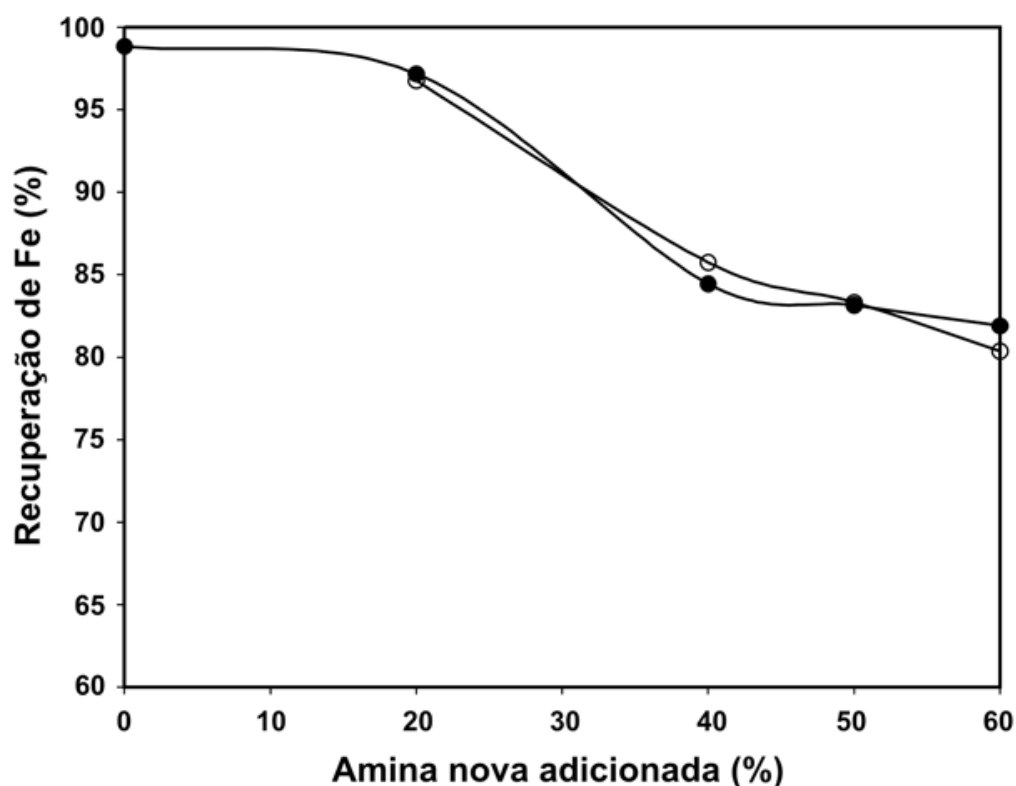

Amina reciclada (EDA 3B) $\quad-$ - Amina reciclada (EDA 3B + F2835)

Figura 5 - Recuperação de ferro no concentrado em função da quantidade de amina adicionada na segunda flotação, para EDA 3B e para a mistura EDA 3B e F2835. 
têm significativa concentração da eteramina e que, ao invés de serem descartadas, podem ser reutilizadas.

Utilizando-se a água contendo as aminas recicladas, juntamente com amina nova, observou-se que há possibilidade de economia de até $50 \%$ desse reagente, gerando grande redução de custos, bem como de descartes para o meio ambiente.

A dessorção da eteramina contida em sólidos, utilizando água, pode ser uma alternativa vantajosa, pois aproximadamente $40 \%$ da amina utilizada nos testes se encontra nessa fração. Além disso, mais de 95\% da amina foi recuperada.

\section{Agradecimentos}

Ao CNPq, pelo suporte financeiro, e ao Departamento de Engenharia de Minas da UFOP, pelo uso da célula de flotação.

\section{Referências bibliográficas}

ALVES, F. Minério de ferro. Revista Brasil Mineral, v. 255, p. 14-20, 2006.

ARAUJO, D.M., YOSHIDA, M.I., CARVAlHO, C.F. Método de quantificação de aminas em resíduos da flotação de minério de ferro. Instituto Nacional da Propriedade Industrial. Patente número PI0705593-5, 2007.

BAHR, A. Amin-Restkonzentrationen in Abwässern der Eisenerzflotation. Erzmetall, 30, p. 12, 1977.

BATISTELI, G.M.B. Amina residual na flotação catiônica reversa de minério de ferro. Universidade Federal de Minas Gerais, 2007. 90p. (Dissertação de Mestrado).

BLEIER, A., GODDARD, E.D., KULKARNI, R.D. The structural effects of amine collectors on the flotation of quartz. In: FUERSTENAU, M.C. Flotation. Society of Mining Engineers, 1976, v. 6, p. 117-147.

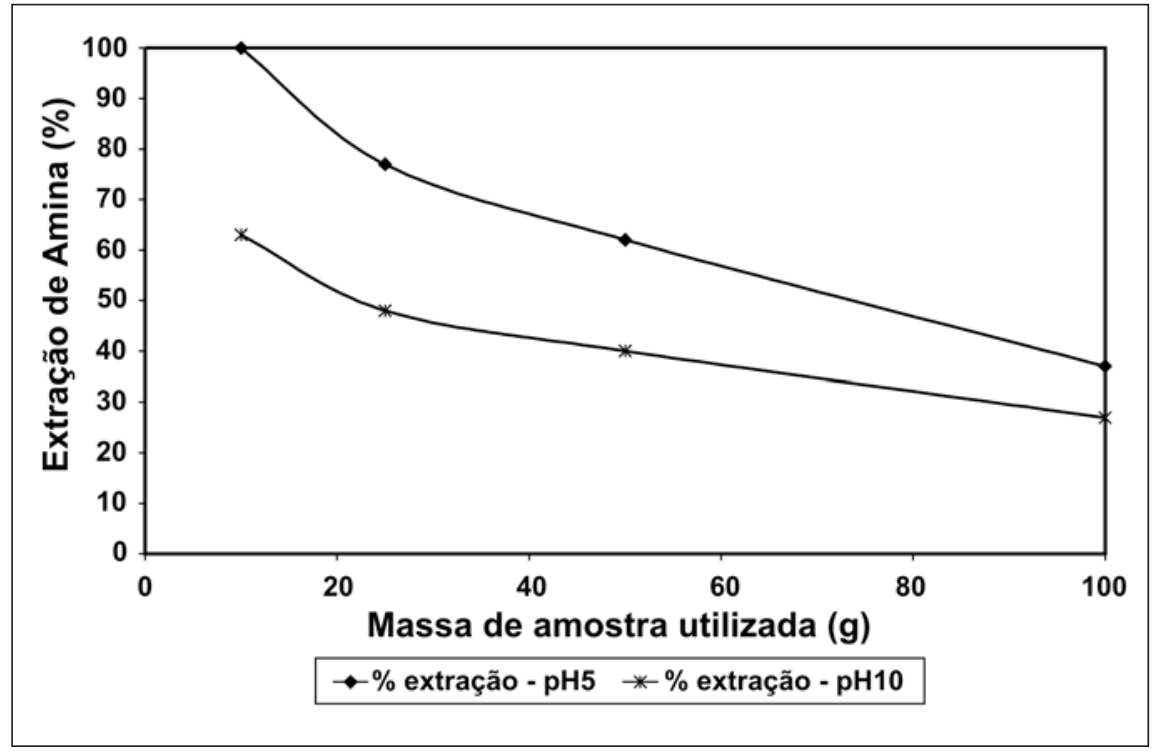

Figura 6 - Rendimento de extração da amina após três etapas de lavagem, em 100ml de água e 30 minutos de contato.

DNPM. Sumário mineral. Departamento Nacional de Produção Mineral, Brasília, 2007.

DNPM. Anuário brasileiro. Departamento Nacional de Produção Mineral. Parte 1, Estatística Brasil, Brasília, 2006.

EMPRESA CLARIANT S.A. Boletim informativo sobre produtos. São Paulo: 1999. 5p.

FUERSTENAU, M.C., HERRERAURBINA, R. Adsorption of cationic surfactants and the flotation of minerals. In: Cationic surfactants: physical chemistry surfactants series. New York: Marcel Dekker, 1991. v. 37, p. 407-447.

HOUOT, R. Beneficiation of iron ore by flotation - review of industrial and potencial applications. International Journal of Mineral Processing, v. 10, p. 183, 1983.

LEJA, J. Flotation surfactants. In: Surface Chemistry of Froth Flotation; New York and London: Plenum Press, 1983. p. 205-339.

NEDER, E.E. $O$ uso das aminas graxas $\boldsymbol{e}$ seus derivados na flotação de minérios brasileiros. Universidade de São Paulo, 2005. 91p. (Dissertação de Mestrado).

NUMELA, W., IWASAKI, I. Iron ore flotation. In: . Advances in Mineral Processing. Colorado: Littleton, 1986. cap. 18.

OLIVEIRA, J.F., WILBERG, K.Q., BALTAR, C.A.M., SOUZA, C.C., ARAÚJO, A.C. Recuperação de amina adsorvida em quartzo ou contida na água flotado visando sua reutilização na flotação reversa de minério de ferro. In: SIMPÓSIO BRASILEIRO DE MINÉRIO DE FERRO, I, 1996, Ouro Preto. Anais... Ouro Preto: ABM, 1996, p. 375-381.

STAPELFELDT, F., CARVALHO, C. F., CHAVES, L.C., REIS, O. B. Quantificação, decomposição e reciclagem de aminas nos resíduos de flotação reversa de minério de ferro. In: ENCONTRO NACIONAL DE TRATAMENTO DE MINÉRIOS, 19. Recife. Anais... Recife: 2002, v. 1, p. 228233.

TEODORO, A.L., LEÃO, V.A. Recuperação de aminas, utilizadas na flotação de minério de ferro, utilizando-se zeólitas naturais. REM - Revista Escola de Minas, v.57, n.3, p. 197-201, 2004.

Artigo recebido em 22/10/2007 e aprovado em 31/05/2008.

\section{REM a primeira revista técnico-científica do Setor Mínero-metalúrgico da América do Sul}

